\title{
EL NUEVO REGLAMENTO (UE) 2019/1111: ANÁLISIS DE LAS MEJORAS EN LAS RELACIONES CON EL CONVENIO DE LA HAYA DE 19 DE OCTUBRE DE 1996 SOBRE RESPONSABILIDAD PARENTAL
}

\author{
THE NEW REGULATION (EU) 2019/1111: ANALYSIS \\ OF THE IMPROVEMENTS IN THE RELATIONS WITH \\ THE HAGUE CONVENTION OF 19 OCTOBER 1996 \\ ABOUT PARENTAL RESPONSIBILITY
}

\author{
Beatriz Campuzano Díaz \\ Profesora Titular de Derecho Internacional Privado \\ Universidad de Sevilla \\ ORCID: 0000-0001-9737-5316
}

Recibido: 15.12.2019 / Aceptado: 10.01.2020

DOI: https://doi.org/10.20318/cdt.2020.5182

Resumen: En materia de responsabilidad parental, el Reglamento 2201/2003 tiene que aplicarse conjuntamente con el Convenio de La Haya de 1996, en el que la Unión Europea ha decidido participar. La coordinación de estos dos instrumentos internacionales ha resultado difícil, en relación particularmente con las normas de competencia judicial internacional. Uno de los objetivos del nuevo Reglamento 2019/1111 ha sido solventar este problema, con la adición de un nuevo párrafo al precepto dedicado a regular las relaciones con el Convenio de La Haya del 96 (art. 61 del Reglamento 2201/2003, ahora art. 97 del Reglamento 2019/1111), que es objeto de análisis en el presente estudio.

Palabras clave: Reglamento 2019/1111, Convenio Haya 1996, coordinación, normas de competencia judicial internacional.

Abstract: In parental responsibility issues, Regulation 2201/2203 has to be applied in conjunction with the 1996 Hague Convention, in which the European Unión has decided to participate. The coordination of these two bodies of international rules has shown to be difficult, particularly in relation with the jurisdiction rules. One of the objectives of new Regulation 2019/1111 is to solve this problem, with the addition of a new paragraph to the article dedicated to regulate the relations with the 1996 Hague Convention (art. 61 of Regulation 2201/2003, now art. 97 of Regulation 2019/1111), which is analysed in this study.

Keywords: Regulation 2019/1111, 1996 Hague Convention, coordination, jurisdiction rules.

Sumario: I. Introducción. II. La participación de la Unión Europea en el CH 96. III. El marco de relaciones entre el Reglamento (UE) 2019/1111 y el CH 96. 1. El Reglamento 2019/1111 y las relaciones con otros instrumentos internacionales. 2. Determinación del ámbito de coincidencia

* Este trabajo se realiza en el marco de las actividades de la Cátedra Jean Monnet sobre derecho de familia y sucesiones en la Unión Europea (Reference number: 599094-EPP-1-ES-EPPJMO-CHAIR), de la que la autora es titular. Las opiniones y valoraciones que se realizan en el presente trabajo son de la exclusiva responsabilidad de la autora. 
entre el Reglamento 2019/1111 y el CH 96. 3. Análisis de la preferencia aplicativa del Reglamento 2019/1111 sobre el CH 96. IV. Las relaciones entre el Reglamento 2019/1111 y el CH 96 en el sector de la competencia judicial internacional. 1. La aplicación del Reglamento 2019/1111 o del CH 96 en función del lugar de residencia habitual del menor. Consecuencias. 2. El foro de la residencia habitual del menor y su relación con la aplicación del Reglamento 2019/1111 o del CH 96. 3. Las reglas especiales de coordinación. A) Cuando las partes han convenido en la competencia de un órgano jurisdiccional de un Estado parte del CH 96. B) La transferencia de la competencia a un órgano jurisdiccional de un Estado parte del CH 96, mejor situado para conocer del asunto. C) La dualidad de procedimientos con un Estado parte del CH 96. V. Conclusiones.

\section{Introducción}

1. El Reglamento (CE) $n^{0} 2201 / 2003$ del Consejo, de 27 de noviembre de 2003, relativo a la competencia, el reconocimiento y la ejecución de las resoluciones judiciales en materia matrimonial y de responsabilidad parental, por el que se deroga el Reglamento (CE) $n^{\circ} 1347 / 2000^{1}$, también conocido como Bruselas II o Bruselas II bis, ha sido objeto de una reciente reforma mediante el Reglamento (UE) 2019/1111 del Consejo, de 25 de junio de 2019, relativo a la competencia, el reconocimiento y la ejecución de resoluciones en materia matrimonial y de responsabilidad parental, y sobre la sustracción internacional de menores (versión refundida) ${ }^{2}$-en adelante, Reglamento 2019/1111-.

2. Si repasamos someramente los hitos fundamentales de este proceso de reforma, hemos de señalar que hubo un primer intento en 2006, que no prosperó. Este año la Comisión presentó la Propuesta de Reglamento del Consejo por el que se modifica el Reglamento (CE) $n^{\circ} 2201 / 2003$ por lo que se refiere a la competencia y se introducen normas relativas a la ley aplicable en materia matrimonial, ${ }^{3}$ con la que se trató de introducir algunos cambios en relación con las normas de competencia judicial internacional en materia matrimonial, además de normas de conflicto uniformes en relación con la separación judicial y el divorcio. El requisito de la unanimidad en el sector del derecho de familia impidió no obstante que pudiera aprobarse esta reforma, optándose finalmente por un Reglamento independiente, limitado a las cuestiones de ley aplicable, que se aprobó a través del sistema de cooperación reforzada: el Reglamento (UE) $n^{\circ} 1259 / 2010$ del Consejo, de 20 de diciembre de 2010, por el que se establece una cooperación reforzada en el ámbito de la ley aplicable al divorcio y a la separación judicial ${ }^{4}$.

3. Con posterioridad se abrió un segundo proceso de reforma, con la publicación por la Comisión, en 2016, de la Propuesta de Reglamento del Consejo relativo a la competencia, el reconocimiento y la ejecución de resoluciones en materia matrimonial y de responsabilidad parental, y sobre la sustracción internacional de menores (refundición). Esta nueva propuesta de reforma del Reglamento 2201/2003,

\footnotetext{
${ }^{1}$ DOUE L 338, de 23 de diciembre de 2003.

2 DOUE L 178, de 2 de julio de 2019.

${ }^{3}$ Bruselas, 17.7.2006, COM (2006) 399 final. Para un análisis de esta Propuesta vid. B. CAmpuzano Díaz, "La propuesta de reforma del Reglamento 2201/2003 en materia matrimonial”, M. di Filippo, B. Campuzano Díaz, A. Rodríguez Benot, M.A. Rodríguez VÁzQuez (coords.), Hacia un derecho conflictual europeo: realizaciones y perspectivas, Sevilla, Secretariado de Publicaciones de la Universidad de Sevilla, 2008, pp. 93 y ss.

${ }^{4}$ DOUE L 343, de 29 de diciembre de 2010.

${ }^{5}$ Bruselas, 30.6.2016, COM (2016) 411 final. Esta Propuesta estuvo precedida de una serie de estudios y acompañada de un análisis de impacto: Vid. Informe de la Comisión al Parlamento Europeo, al Consejo y al Comité Económico y Social Europeo sobre la aplicación del Reglamento (CE) $n^{\circ} 2201 / 2003$ del Consejo, de 27 de noviembre de 2003, relativo a la competencia, el reconocimiento y la ejecución de las resoluciones judiciales en materia matrimonial y de responsabilidad parental, por el que se deroga el Reglamento (CE) $n^{\circ}$ 1347/2000, Bruselas, 15.4.2014 COM (2014) 225 final. Study on the assessment of Regulation (EC) Núm. 2201/2003 and the policy options for its amendment, final report, evaluation (https://publications.europa.eu/en/ publication-detail/-/publication/463a5c10-9149-11e8-8bc1-01aa75ed71a1/language-en); Study on the assessment of Regulation (EC) Num. 2201/2003 and the policy options for its amendment, final report, analytical annexes, (https://publications.europa.eu/en/publication-detail/-/publication/924728ec-9148-11e8-8bc1-01aa75ed71a1/language-en); Study on the assessment of Regulation (EC) No 2201/2003 and the policy options for its amendment, final report, executive summary (https://publications.europa.eu/en/publication-detail/-/publication/dabe9a09-9147-11e8-8bc1-01aa75ed71a1/language-en). Commission staff working document. Impact assessment accompanying the document: Proposal for a Council Regulation on jurisdiction, the re-
} 
de mayor calado que la anterior, afectaba fundamentalmente al secuestro internacional de menores, al reconocimiento y la ejecución de resoluciones, así como a la cooperación de autoridades. En relación con las normas de competencia judicial internacional se proponían pocos cambios y vinculados, fundamentalmente, a las normas en materia de responsabilidad parental. Sin duda, las dificultades experimentadas con el requisito de la unanimidad en relación con la propuesta de reforma anterior, llevaron a que en la materia matrimonial se mantuvieran básicamente las mismas soluciones y a que el ánimo reformista fuera algo más amplio en las cuestiones de responsabilidad parental, con el fin, básicamente, de mejorar las relaciones entre el Reglamento 2201/2003 y el Convenio de La Haya de 19 de octubre de 1996 relativo a la competencia, la ley aplicable, el reconocimiento, la ejecución y la cooperación en materia de responsabilidad parental y de medidas de protección de los niños ${ }^{6}$-en adelante CH 96-, así como de incorporar los pronunciamientos del TJUE en relación con aquellos preceptos que habían venido suscitando dificultades interpretativas?

4. Sobre el proceso de tramitación ${ }^{8}$ puede señalarse que el Comité Económico y Social aprobó su Dictamen en el pleno de 26 de enero de $2017^{9}$. El Parlamento Europeo aprobó una primera Resolución legislativa sobre la Propuesta el 18 de enero de $2018^{10}$, que en una fase avanzada de las negociaciones y teniendo en cuenta la postura del Consejo, se vio seguida de una segunda Resolución de 14 de marzo de $2019^{11}$. El Consejo adoptó el Reglamento por unanimidad en su sesión de 25 de junio de $2019^{12}$.

5. El Reglamento (UE) 2019/1111 comenzará a aplicarse a partir del 1 de agosto de 2022 (art. 105). Tiempo habrá por tanto para analizar en detalle las disposiciones de este nuevo Reglamento, que conformará el núcleo del Derecho internacional privado de la Unión Europea en materia de familia ${ }^{13}$.

cognition and enforcement of decisions in matrimonial matters and the matters of parental responsibility, and on international child abduction (recast), Brussels 30.6.2016 SWD (2016) 207 final); Commission staff working document. Executive summary of the impact assessment accompanying the document: Proposal for a Council Regulation on jurisdiction, the recognition and enforcement of decisions in matrimonial matters and the matters of parental responsibility, and on international child abduction (recast), Brussels 30.6.2016 SWD (2016) 208 final.

${ }^{6} \mathrm{BOE} \mathrm{n}^{\circ} 291$, de 2 de diciembre de 2010.

${ }^{7}$ Al respecto vid. B. CAMPuZano Díaz, "La propuesta de reforma del Reglamento 2201/2003: ¿se introducen mejoras en la regulación de la competencia judicial internacional?”, M. GuZmán Zapater y C. Esplugues Mota (dirs.) y M. Herranz Ballesteros y M. Vargas Gómez Urrutia (coords.), Persona y familia en el nuevo modelo español de Derecho internacional privado, Tirant lo Blanch, Valencia, 2017, pp. 91 y ss.

${ }^{8}$ Una información muy completa sobre este proceso puede encontrarse en: https://eur-lex.europa.eu/procedure/EN/2016_190

9 Dictamen del Comité Económico y Social Europeo sobre la Propuesta de Reglamento del Consejo relativo a la competencia, el reconocimiento y la ejecución de resoluciones en materia matrimonial y de responsabilidad parental, y sobre la sustracción internacional de menores (refundición), DOUE C 125, de 21 de abril de 2017.

${ }^{10}$ Resolución legislativa del Parlamento Europeo, de 18 de enero de 2018, sobre la propuesta de Reglamento del Consejo relativo a la competencia, el reconocimiento y la ejecución de resoluciones en materia matrimonial y de responsabilidad parental, y sobre la sustracción internacional de menores (refundición) (COM(2016)0411 - C8-0322/2016 - 2016/0190(CNS)), http://www.europarl.europa.eu/doceo/document/TA-8-2018-0017_ES.html. Esta Resolución estuvo precedida de un Informe de 30 de noviembre de 2017 de la Comisión de Asuntos Jurídicos, Ponente T. ZWIEFKA, sobre la propuesta de Reglamento del Consejo relativo a la competencia, el reconocimiento y la ejecución de resoluciones en materia matrimonial y de responsabilidad parental, y sobre la sustracción internacional de menores (refundición) (COM(2016)0411 - C8-0322/2016 2016/0190(CNS)), http://www.europarl.europa.eu/doceo/document/A-8-2017-0388_ES.html

${ }^{11}$ Resolución legislativa del Parlamento Europeo de 14 de marzo de 2019 sobre la propuesta de Reglamento del Consejo relativo a la competencia, el reconocimiento y la ejecución de resoluciones en materia matrimonial y de responsabilidad parental, y sobre la sustracción internacional de menores (versión refundida) (15401/2018 - C8-0023/2019 - 2016/0190(CNS)), http://www.europarl.europa.eu/doceo/document/TA-8-2019-0206_ES.html

${ }^{12}$ Los documentos sobre el proceso de negociación en el Consejo y la adopción final del Reglamento pueden consultarse a través de Internet, vid supra nota 8 .

${ }^{13}$ Sí disponemos ya de numerosos trabajos relacionados con el proceso de reforma, que se han centrados en diferentes aspectos del Reglamento. Vid. M.C. BARUFFI, "A child-friendly area of freedom, security and justice: work in progress in international child abduction cases", Journal of private international law, Vol. 14, № 3, 2018, pp. 385 y ss.; A. BonOMI, "La compétence internationale en matière de divorce. Quelques suggestions pour une (improbable) révision du règlement Bruxelles II bis", Revue critique de droit international privé, 2017, $\mathrm{n}^{\circ}$ 4, pp. 511 y ss.; P. Beaumont, L. Walker y J. Holliday, "Parental responsibility and international child abduction in the proposed recast of the Brussels IIa Regulation and the effect of Brexit on future child abduction proceedings", International family law journal, 2016, pp. 307 y ss.; J. Borg BARTHET, "Jurisdiction in matrimonial matters - Reflections for the review of the Brussels IIa Regulation”, PE 571.361, http://www.europarl.europa.eu/ 
Nosotros en las líneas que siguen nos vamos a centrar en un aspecto muy concreto, que consideramos de interés.

6. La actuación incesante de la Unión Europea en el sector del Derecho internacional privado plantea ciertas dificultades de interacción con los Convenios promovidos por otras organizaciones internacionales, y en particular, por la Conferencia de La Haya de Derecho Internacional Privado. La Unión Europea no pretende limitar su actuación a las relaciones jurídico-privadas que se desarrollan en el interior de este espacio de integración, sino que tiene la mira puesta más allá, como evidencia el hecho de que es miembro de pleno derecho de la Conferencia de La Haya ${ }^{14}$. Se puede decir por tanto que la unificación regional a nivel europeo se realiza sin perder de vista la pretendida unificación universal que protagoniza la Conferencia de La Haya, lo cual exige tender puentes que no siempre resultan fáciles de diseñar. Uno de los objetivos del Reglamento 2019/1111 ha sido, precisamente, mejorar las relaciones con el CH 96. Al análisis de las modificaciones que se introducen en el nuevo Reglamento para lograr tal objetivo vamos a dedicar las líneas que siguen ${ }^{15}$.

\section{La participación de la Unión Europea en el CH 96}

7. Como acabamos de señalar, la Unión Europea no pretende limitar su ámbito de actuación a las relaciones jurídico-privadas que se desarrollan en el interior de este espacio de integración, sino que se preocupa también de la dimensión exterior y, en consecuencia, de las iniciativas de unificación normativa para las relaciones jurídico-privadas conectadas con terceros Estados. Esta preocupación suscitó un intenso

RegData/etudes/STUD/2016/571361/IPOL_STU(2016)571361_EN.pdf; A. BorRÁs, "Grounds of jurisdiction in matrimonial matters; recasting the Brussels IIa Regulation", Nederlands internationaal privaatrecht, 2015, No 1, pp. 2 y ss.; L. CARPANETO, "La ricerca de una (nuova) sintesi tra interesse superiore del minore in astratto e in concreto nella riforma del Regolamento Bruxelles II-bis", Rivista di diritto internazionale privato e processuale, Vol. LIV, nº 4, 2018, pp. 944 y ss.; TH.M. DE BoER, "What we should not expect from a recast of the Brussels IIbis Regulation", Nederlands internationaal privaatrecht, 2015, N ${ }^{\circ} 1$, pp. 10 y ss.; F.J. ForCADA Miranda, "Revision with respect to the cross-border placement of children", Nederlands internationaal privaatrecht, 2015, No 1, pp. 36 y ss.; M.A. Gandía Sellens, "La responsabilidad parental y la sustracción de menores en la propuesta de la Comisión para modificar el RBII bis: algunos avances, retrocesos y ausencias", Anuario español de Derecho internacional privado, t. XVII, 2017, pp. 799 y ss.; C. HoNORATI, "La proposta di revisione del Regolamento Bruxelles II-Bis: più tutela per i minori e più eficacia nell'esecuzione delle decisioni”, Rivista di diritto internazionale privato e processuale, Vol. LIII, $\mathrm{n}^{\circ} 2$ 2, 2017, pp. 247 y ss.; C. HonORATI, “The Commission's proposal for a recast of Brussels IIa Regulation”, International family law journal, 2017, № 1, pp. 97 y ss.; Recasting the Brussels IIa Regulation. Workshop 8 November 2018, PE 571.38,

http://www.europarl.europa.eu/RegData/etudes/STUD/2016/571383/IPOL_STU\%282016\%29571383_EN.pdf; T. KRUGER, "Brussels IIa recast moving forward”, Nederlands internationaal privaatrecht, 2017, No 3, pp. 462 y ss.; T. KRUGER \& L. SAMYN, "Brussels II bis: successes and suggested improvements", Journal of private international law, Vol. 12, № 1, 2016, pp. 132 y ss.; M. Mellone, "Provisional measures and the Brussels II bis Regulation: an assessment of the status quo in view of future legislative amendments", Nederlands internationaal privaatrecht, 2015, No 1, pp. 20 y ss.; A. Quirós Fons, "Reforma del Reglamento Bruselas II bis y reconocimiento de decisions eclesiásticas en el ultimo Estado miembro de la UE", Bitacora Millenium DIPr, nº 7, 2018; E. Rodríguez Pineau, "La refundición del Reglamento Bruselas II bis: de nuevo sobre la función del Derecho internacional privado europeo", Revista española de Derecho internacional, Vol. 69, № 1, 2017, pp. 139 y ss.; Ma..A. Rodríguez VÁzquez, "La reforma del Reglamento (CE) No 2201/2003: análisis de las soluciones propuestas en materia de reconocimiento y ejecución de resoluciones", Anuario español de Derecho internacional privado, t. XVII, 2017, pp. 767 y ss.; C. Ruiz Sutil, "Implementación del Convenio de Estambul en la refundición del Reglamento Bruselas II bis y su repercusión en la sustracción internacional de menores", Cuadernos de derecho transnacional, Vol. 10, N 2, 2018, pp. 615 y ss.; J.M. Sсотт, "A question of trust? Recognition and enforcement of judgments", Nederlands internationaal privaatrecht, 2015, $\mathrm{N}^{\mathrm{o}}$ 1, pp. 26 y ss.; A.S. DE Sousa GonÇALves, "Wrongful removal or retention of children and the Brussels IIa proposed recast", Anuario español de Derecho internacional privado, t. XVIII, 2018, pp. 351 y ss.; B. UBERTAZZI, "The hearing of the child in the Brussels IIa Regulation and its recast proposal", Journal of private international law, Vol. 13, No 3, 2017, pp. 568 y ss.; H. VAN Loon, “The Brussels IIa Regulation: towards a review?", Cross-Border activities in the EU-making life easier for citizens, $\mathrm{PE}$ 510.003, http:/www.europarl.europa.eu/RegData/etudes/STUD/2015/510003/IPOL_STU(2015)510003_EN.pdf.

14 Vid. infra nota 8.

${ }^{15}$ A esta cuestión hemos dedicado un estudio previo, de alcance más limitado, que se encuentra en prensa: B. CAMPUZANO DíAz, "La unificación del Derecho internacional privado en la Unión Europea y los convenios de la Conferencia de La Haya: una mejor coordinación en materia de responsabilidad parental, a propósito del nuevo Reglamento 2019/1111”, A. BELTRAME DE Moura (dir.), O direito internacional privado europeu entre a harmonizaçao e da fragmentaçao, Emais editora, Florianopolis. 
debate, del que el Dictamen del TJCE 1/03, de 7 de febrero de 2006, "Competencia de la Comunidad para celebrar el nuevo Convenio de Lugano relativo a la competencia judicial, al reconocimiento y a la ejecución de resoluciones judiciales en materia civil y mercantil ${ }^{16}$, puede considerarse un punto de inflexión. Se discutía, en este caso, cuál debía ser el papel de las instituciones europeas y de los Estados miembros en la negociación del nuevo Convenio, concluyendo el TJCE con una interpretación extensiva de las circunstancias en que podía verse afectada la normativa europea en virtud del Convenio, que era el factor determinante para que la competencia correspondiese con carácter exclusivo a las instituciones europeas ${ }^{17}$. En este contexto, en que la Unión Europea asumía un protagonismo creciente como actor internacional, hay que situar el hecho de que se convirtiera en miembro de pleno derecho de la Conferencia de La Haya de Derecho Internacional Privado $^{18}$, para lo que fue necesario que esta organización modificara su Estatuto ${ }^{19}$.

8. Como el CH 96 es anterior a estos acontecimientos, en su articulado aún no se contemplaba la posibilidad de que pudieran ser parte del mismo organizaciones regionales de integración económica. Por ello, y dado que el contenido del CH 96 afectaba al Reglamento 1347/2000, después transformado en el Reglamento 2001/2003, hubo que aprobar dos decisiones autorizando a los Estados miembros a firmar y posteriormente ratificar o adherirse al CH 96 en interés de la Unión Europea. Se trató de la Decisión del Consejo, de 19 de diciembre de 2002, por la que se autoriza a los Estados miembros a firmar, en interés de la Comunidad, el Convenio de La Haya de 1996 relativo a la competencia, la ley aplicable, el reconocimiento, la ejecución y la cooperación en materia de responsabilidad parental y de medidas de protección de los niños ${ }^{20}$, y de la Decisión del Consejo, de 5 de junio de 2008, por la que se autoriza a algunos Estados miembros a ratificar o adherirse, en interés de la Comunidad Europea, al Convenio de La Haya de 1996 relativo a la competencia, la ley aplicable, el reconocimiento, la ejecución y la cooperación en materia de responsabilidad parental y medidas de protección de los niños, y por la que se autoriza a algunos Estados miembros a formular una declaración sobre la aplicación de las normas internas correspondientes del Derecho comunitario ${ }^{21}$.

9. En virtud de ello se puede decir que hoy día todos los Estados miembros de la Unión Europea son parte del $\mathrm{CH} 96$, aunque las fechas de incorporación a este instrumento internacional han sido dispares ${ }^{22}$.

\section{El marco de relaciones entre el Reglamento (UE) 2019/1111 y el CH 96}

\section{El Reglamento 2019/1111 y las relaciones con otros instrumentos internacionales}

10. El Reglamento 2019/1111, al igual que el Reglamento 2201/2003, contiene una serie de disposiciones finales para regular sus relaciones con otros instrumentos internacionales. Se establece con carácter general, en su art. 94.1, que el Reglamento 2019/1111 sustituirá a los convenios celebrados entre dos o más Estados miembros en las materias a las que este instrumento se refiere. En el art. 95 se

\footnotetext{
${ }^{16}$ ECLI:EU:C:2006:81.

${ }^{17}$ Para un análisis más amplio de esta cuestión vid. B. Campuzano Díaz, "La política legislativa de la UE en DIPr. de familia. Una valoración de conjunto", Cuadernos de Derecho Transnacional, Vol. 5, No 2, 2013, pp. 243 y ss.

${ }^{18}$ Se solicitó formalmente la adhesión a la Conferencia de La Haya de Derecho Internacional Privado mediante Decisión de 5 de octubre de 2006 (2006/719/CE), DOUE L 297, de 26 de octubre de 2006. La adhesión se formalizó en el Consejo de Política y Asuntos Generales de la Conferencia de 3 de abril de 2007, Vid. A. Borrás, "La Comunidad Europea como miembro de la Conferencia de La Haya de Derecho internacional privado", Anuario español de Derecho internacional privado, t. VI, 2006, pp. 1179 y ss.

${ }^{19}$ Enmiendas al Estatuto de la Conferencia de La Haya de Derecho Internacional Privado, hecho en La Haya el 31 de octubre de 1951, adoptadas por la Conferencia de La Haya de Derecho Internacional Privado, en su vigésima reunión celebrada en La Haya, el 30 de junio de 2005, y texto consolidado de dicho Estatuto, BOE nº 77, de 30 de marzo de 2012.

20 DOUE L 48, de 21 de febrero de 2003.

${ }^{21}$ DOUE L 151, de 11 de junio de 2008.

${ }^{22}$ Sobre las dificultades que se plantearon durante el proceso de incorporación de los Estados miembros de la Unión Europea al CH 96, vid. S. Armstrong, "L'articulation des règlements communautaires et des conventions de La Haye", H. FulCHIRON y C. NouRISSAT, Le nouveau droit communautaire du divorce et de la responsabilité parentale, Dalloz, 2005, pp. 120-121.
} 
mencionan determinados convenios multilaterales, entre los que figuran varios acuerdos promovidos por la Conferencia de La Haya de Derecho Internacional Privado, reiterándose que en las relaciones entre los Estados miembros primará el Reglamento. Se trata de la misma lista que recoge el Reglamento 2201/2003 en su art. 60, con la salvedad de que en el nuevo Reglamento se dedica un artículo específico a regular las relaciones con el Convenio de La Haya de 25 de octubre de 1980 sobre los aspectos civiles de la sustracción internacional de menores ${ }^{23}$.

11. Concretamente, en el art. 96 del Reglamento $2019 / 1111$ se estable que cuando un menor esté retenido o haya sido trasladado ilícitamente a un Estado miembro distinto del Estado miembro en donde el menor tenía su residencia habitual inmediatamente antes de su traslado o retención ilícitos, seguirán aplicándose las disposiciones del Convenio de La Haya de 1980 tal y como quedan completadas con los Capítulos III y IV del presente Reglamento. Se añade, a continuación, que cuando una resolución por la que se ordene la restitución de un menor con arreglo al Convenio de La Haya de 1980 haya sido dictada en un Estado miembro y deba reconocerse y ejecutarse en otro Estado miembro tras el traslado o la retención ilícitos del menor, será de aplicación el Capítulo IV. Esta nueva disposición hay que valorarla positivamente, pues refleja más fielmente la relación de complementariedad que se establece entre el Convenio de La Haya del 80 y el Reglamento, consistente en la modificación de determinados aspectos del Convenio para su aplicación entre los Estados miembros, además del recurso complementario a sus normas sobre reconocimiento y ejecución ${ }^{24}$.

12. El art. 97 del Reglamento 2019/1111 es el que se dedica a regular las relaciones con el CH 96 y es en el que vamos a centrar nuestra atención. Nos encontramos con un artículo que ha sido reformado con respecto al Reglamento 2201/2003, añadiéndosele un nuevo apartado con el fin de mejorar los problemas interpretativos que venían suscitándose con las normas de competencia judicial internacional. Este precepto se complementa con el art. 98 , que establece en su aptdo. $1^{\circ}$ que los Convenios mencionados en los artículos precedentes seguirán surtiendo efectos en las materias que no están reguladas por el Reglamento, refiriéndose a continuación en su aptdo. $2^{\circ}$ al CH 96, para señalar que seguirá surtiendo efecto entre los Estados miembros dentro del respeto a lo dispuesto en el art. 97.

\section{Determinación del ámbito de coincidencia entre el Reglamento 2019/1111 y el CH 96}

13. No existe una completa identidad de contenidos entre el Reglamento 2019/1111 y el CH 96. El Reglamento 2019/2011 se ocupa del divorcio, la separación judicial y la nulidad del matrimonio, así como de las cuestiones de responsabilidad parental, con normas que regulan la competencia judicial internacional, el reconocimiento y ejecución de resoluciones, y la cooperación internacional de autoridades. No regula las cuestiones de ley aplicable, que sí se regulan en el CH 96, además de los otros aspectos mencionados. Por otra parte, el CH 96 se limita a las cuestiones de responsabilidad parental y medidas de protección de los niños, sin ocuparse de la materia matrimonial.

14. El ámbito de coincidencia entre ambos instrumentos internacionales, una vez descartada la materia matrimonial, se reduce por tanto a las cuestiones de responsabilidad parental y medidas de protección de los niños. En esta materia, el Reglamento 2019/1111 ha venido a pronunciarse expresamente sobre una cuestión que redunda en un mayor paralelismo de soluciones con el $\mathrm{CH}$ 96. El Convenio delimita su ámbito de aplicación en el art. 2, refiriéndose a que se aplica a los niños hasta que alcancen

\footnotetext{
${ }^{23}$ BOE núm. 202, de 24 de agosto de 1987.

24 Esta aclaración sobre la particular naturaleza de las relaciones entre estos dos instrumentos internacionales también se ha llevado al art. 1.3 del Reglamento 2019/1111: "3. Los capitulos III y IV del presente Reglamento se aplican en casos de traslado o retención ilícitos de un menor que afecten a más de un Estado miembro, completando el Convenio de La Haya de 1980 . El capítulo IV del presente Reglamento se aplica a resoluciones que ordenen la restitución de un menor a otro Estado miembro de conformidad con el Convenio de La Haya de 1980 que deban ser ejecutadas en un Estado miembro distinto del Estado miembro donde se dictó la resolución".
} 
la edad de dieciocho años. El Reglamento 2201/2003, que prefiere usar la palabra menores, guarda silencio sobre esta cuestión, que sí aborda en el Reglamento 2019/1111, donde se señala que se entiende por menor toda persona que tenga menos de dieciocho años (art. 2.2.6 $)^{25}$.

15. En cuanto a la lista de materias incluidas y excluidas del concepto de responsabilidad parental y de medidas de protección del menor, hemos de señalar que se hace una enumeración en ambos instrumentos muy parecida (arts. 1.2 y 1.3 del Reglamento 2019/1111 y arts. 3 y 4 CH 96) ${ }^{26}$. El CH 96 también se refiere, entre las materias incluidas, a las medidas de supervisión que puedan desarrollar las autoridades públicas, del cuidado dispensado al niño por toda persona que lo tenga a su cargo (art. 3.f). Ello no supone una diferencia con el Reglamento, que también se aplica a las medidas que puedan adoptar las autoridades públicas, a pesar de referirse en su art. 1 a materias civiles, tal como el TJUE ha tenido ocasión de aclarar en diversas ocasiones ${ }^{27}$. Esta jurisprudencia se ha incorporado ahora además al Preámbulo del Reglamento 2019/1111, cuando se refiere a su ámbito de aplicación en el Considerando $4^{28}$.

16. Siguiendo con la determinación del ámbito de coincidencia entre el Reglamento 2019/1111 y el $\mathrm{CH} 9$, ya hemos tenido ocasión de señalar que el Reglamento no se ocupa de las cuestiones de ley aplicable, de las que sí se ocupa el CH 96, en sus arts. 15 y ss. Serán por tanto las normas de conflicto contenidas en este Convenio a las que tendrán que acudir en todo caso las autoridades de los Estados miembros para determinar la ley aplicable, cuando resulten competentes. Esta conclusión se extrae del art. 98.1 del Reglamento, al que ya hemos tenido ocasión de referirnos, donde se establece que los acuerdos y convenios mencionados en los artículos precedentes, entre ellos el CH 96, seguirán surtiendo efectos en las materias que no estén reguladas por el Reglamento. Pero además, dado que el tenor literal de las normas de con-

${ }^{25}$ En el Considerando 17 se explica el sentido de esta referencia expresa a los menores de dieciocho años, poniendo de manifiesto el deseo de que exista una adecuada coordinación del Reglamento 2019/1111 con el CH 96 y otros convenios de la Conferencia de la Haya: "El presente Reglamento, al igual que el Convenio de La Haya de 19 de octubre de 1996 relativo a la competencia, la ley aplicable, el reconocimiento, la ejecución y la cooperación en materia de responsabilidad parental y de medidas de protección de los niños (en lo sucesivo, «Convenio de La Haya de 1996»), debe aplicarse a todos los menores de 18 años, incluso cuando hayan adquirido capacidad antes de esa edad en virtud de su ley personal, por ejemplo en casos de emancipación por matrimonio. Esto debe evitar toda posible superposición con el ámbito de aplicación del Convenio de La Haya de 13 de enero de 2000 sobre protección internacional de los adultos, que se aplica desde los 18 años en adelante, y al mismo tiempo, evitar lagunas entre los dos instrumentos. En el caso de los menores de hasta 16 años, debe seguir aplicándose el Convenio de La Haya de 1980 y, por lo tanto, también el capitulo III del presente Reglamento, que complementa la aplicación del Convenio de La Haya de 1980 en las relaciones entre los Estados miembros". La aclaración que se realiza en relación con los menores emancipados debe valorarse positivamente, pues no todos los Estados miembros conocen la figura de la emancipación y ello podría dar lugar a diferencias aplicativas (al respecto vid. P. Orejudo Prieto de los Mozos, "Diez años de aplicación e interpretación del Reglamento Bruselas II bis sobre crisis matrimoniales y responsabilidad parental (análisis de los aspectos de competencia judicial internacional)", La Ley Unión Europea, n 21, 2014, p. 9. Por otra parte, aunque en la Unión Europea no se ha regulado la protección internacional de adultos, sí hay varios Estados miembros que participan en el mencionado Convenio de La Haya de 13 de enero de 2000 y era conveniente aclarar las relaciones con este Instrumento.

${ }^{26}$ Tal como se ha puesto de manifiesto, tanto en relación con la lista de materias incluidas por el Reglamento 2201/2003 (ahora Reglamento 2019/1111) dentro del concepto de responsabilidad parental, como en relación con la lista de materias excluidas, se observa una clara influencia de los arts. 3 y 4 CH 96, W. Pintens, "Article 1: Scope”, U. Magnus y P. MANKowsKi (eds.), European Commentaries on Private International Law, Volume IV Brussels II bis Regulation, Otto Schmidt, Colonia, 2017, p. 79. Alguna de las diferencias observables entre el Reglamento 2019/1111 y el CH 96 obedece al mayor ámbito de aplicación geográfico de este último, como es la referencia que se hace en su art. 3.e) al cuidado del niño mediante kafala.

${ }^{27}$ Sentencia del TJCE de 27 de noviembre de 2007, C, As. 435/06, ECLI:EU:C:2007:714; Sentencia del TJCE 2 de abril de 2009, A, As. 523/07, ECLI:EU:C:2009:225; Sentencia del TJUE de 26 de abril de 2012, Health Service Executive, As. 92/12, ECLI:EU:C:2012:255. Al respecto vid. K. Boele-WoelKI y M. JANTERA JÄReBorg, "Protecting children against detrimental family environments under the 1996 Hague Convention and the Brussels II bis Regulation", K. Boele-WoelKi, T. EINHORN, D. Girsberger, S. Symeonides (eds.), Convergence and divergence in private international law. Liber amicorum K. Siehr, Schulthess, Zúrich, 2010, p. 140.

28 "La noción de «materia civil» debe interpretarse de forma autónoma, de conformidad con la jurisprudencia consolidada del Tribunal de Justicia. Debe ser considerada un concepto independiente que se ha de interpretar remitiéndose, en primer lugar, a los objetivos y al régimen del presente Reglamento y, en segundo lugar, a los principios generales que se deducen del conjunto de los sistemas jurídicos nacionales. Por consiguiente, el concepto de «materia civil» debe interpretarse en el sentido de que también puede abarcar medidas que, desde el punto de vista del sistema jurídico de un Estado miembro, pueden estar sometidas al Derecho público. Debe abarcar en particular todas las demandas, medidas o resoluciones en materia de "responsabilidad parental» en el sentido del presente Reglamento, de conformidad con sus objetivos". 
flicto contenidas en el CH 96 no estaba bien adaptado a la relación que se establece con el Reglamento, concretamente el art. $15 \mathrm{CH}$ 96, se ha querido evitar cualquier duda al respecto, con un considerando explicativo en el Preámbulo del Reglamento 2019/1111. Concretamente, en el Considerando 92 se señala que la legislación aplicable en materia de responsabilidad parental debe determinarse de conformidad con las disposiciones del Capítulo III del Convenio de La Haya de 1996, y que al aplicarse este Convenio en un procedimiento ante un órgano jurisdiccional de un Estado miembro en el que se aplique el presente Reglamento, la referencia que se hace en el art. $15.1 \mathrm{CH} 96$ a las disposiciones de su Capítulo II -que se refiere a las normas de competencia-, se entenderá hecha a las disposiciones del Reglamento ${ }^{29}$.

17. La realidad es que el carácter erga omnes de las normas de conflicto habría hecho imposible una convivencia de dos instrumentos internacionales referidos a la misma materia. El CH 96 posibilita la unificación conflictual entre los Estados miembros, necesaria para la consecución del principio de reconocimiento mutuo, con la ventaja añadida de que se trata de una unificación conflictual que va más allá del ámbito europeo, dado que no son pocos los terceros Estados que han decidido participar en este instrumento internacional ${ }^{30}$.

\section{Análisis de la preferencia aplicativa del Reglamento 2019/1111 sobre el CH 96}

18. El art. 97.1 del Reglamento 2019/1111 dispone básicamente lo mismo que el Reglamento 2201/2003 en su art. 61: "En las relaciones con el Convenio de La Haya de 1996, el presente Reglamento se aplicará: a) a reserva de lo dispuesto en el apartado 2 del presente artículo, cuando el menor tenga su residencia habitual en el territorio de un Estado miembro; b) en lo que respecta al reconocimiento y ejecución en el territorio de un Estado miembro de una decisión dictada por un órgano jurisdiccional de otro Estado miembro, aun cuando el menor afectado tenga su residencia habitual en un Estado que sea parte contratante del citado Convenio y en el que no se aplique el presente Reglamento".

19. Para que pudiera incluirse este precepto en el Reglamento se contó con la colaboración de la Conferencia de la Haya de Derecho Internacional Privado. El CH 96 es anterior en el tiempo al primer Reglamento que la Unión Europea dedicó a las cuestiones de responsabilidad parental (el Reglamento 1347/2000, después sustituido por el Reglamento 2201/2003, y ahora por el Reglamento 2019/1111), pero ya durante su proceso de negociación se sabía que los países de la Unión Europea tenían intención de aprobar una normativa de carácter regional ${ }^{31}$. En consecuencia, se decidió incorporar al CH 96 un precepto que permitiera a los Estados miembros de la Unión Europea participar en este instrumento internacional, sin comprometer una futura regulación entre ellos. Concretamente, el art. 52.2 CH 96 dispone que el Convenio no afectará a la posibilidad para uno o varios Estados contratantes de concluir acuerdos que contengan disposiciones sobre las materias reguladas por el presente Convenio, respecto a niños que tengan su residencia habitual en uno de los Estados parte en tales acuerdos. La incorpora-

${ }^{29}$ En la Propuesta inicialmente presentada por la Comisión (vid. supra nota 5) esta precisión se incorporaba en el artículo del Reglamento que regulaba las relaciones con el CH 96 (art. 75 de la Propuesta, ahora art. 97 del Reglamento 2019/1111), que estimamos que era el lugar más apropiado. Algunos autores iban más allá, sugiriendo incluso que podía haberse incorporado en el articulado del Reglamento una sección sobre derecho aplicable, con una referencia expresa al CH 96, de forma similar a como se hace en otros Reglamentos, H. VAN Loon, “The Brussels IIa Regulation: towards a review?” op. cit., p. 200; L. CARPANETO, "La ricerca de una (nuova) sintesi tra interesse superiore del minore in astratto e in concreto nella riforma del Regolamento Bruxelles II-bis”, op. cit., p. 954. Esta posibilidad no era en nuestra opinión la más adecuada, dado que el Reglamento 2019/1111 también se ocupa de las crisis matrimoniales y en relación con esta materia no habría sido posible incorporar la misma referencia, considerando que se regula en el Reglamento 1259/2010, que sólo se aplica en algunos Estados miembros por haberse adoptado a través de cooperación reforzada.

${ }^{30}$ La lista de Estados parte del CH 96 se eleva a 52. Se puede consultar en www.hcch.net.

31 E. Gallant, Responsabilité parentale et protection des enfants en droit international privé, París, Defrénois, 2004, p. 87. No debe olvidarse que con anterioridad al primer Reglamento dedicado a esta materia ya se había negociado un Convenio con arreglo al artículo K.3 del Tratado de la Unión Europea, sobre la competencia, el reconocimiento y la ejecución de resoluciones judiciales en materia matrimonial, aprobado por el Consejo el 28 de mayo de 1998, que afectaba a las cuestiones de responsabilidad parental. 
ción de esta "cláusula de desconexión negociada" al CH 96 no fue precisamente pacífica ${ }^{32}$, y de hecho, las dificultades que entonces se plantearon con su redacción sirvieron para anticipar los problemas de interacción que podían surgir con la normativa europea, como efectivamente después sucedió.

20. En el sector de la competencia judicial internacional, el art. 97.1.a) del Reglamento 2019/1111 determina, a reserva de lo dispuesto en el aptdo. $2^{\circ}$, que la norma europea será de aplicación preferente cuando el menor tenga su residencia habitual en un Estado miembro. Tal como se deduce, por otra parte, de lo dispuesto en el art. 52.2 CH 96, se aplicarán las normas de este Convenio cuando el niño tenga su residencia habitual en un Estado parte del mismo, en el que no se aplique el Reglamento. En definitiva, que las autoridades de los Estados miembros de la Unión Europea, que son a fin de cuentas las que podrían aplicar las normas de competencia judicial internacional de ambos instrumentos internacionales, tendrán que recurrir a las normas del Reglamento 2019/1111 en el primer supuesto y a las del CH 96 en el segundo.

21. Esta solución, que ya se recogía en el art. 61 del Reglamento 2201/2003, es en apariencia sencilla. No obstante, en la práctica se ha demostrado que plantea problemas interpretativos, además de que no viene a dar una respuesta adecuada en relación con todas las normas reguladoras de la competencia judicial internacional. La reforma introducida por el Reglamento 2019/1111, con la incorporación del mencionado aptdo. $2^{\circ}$ del art. 97, va encaminada a solventar las carencias previamente detectadas. Sobre esta cuestión volveremos en el siguiente epígrafe.

22. En el sector del reconocimiento y ejecución de resoluciones, las relaciones entre la normativa europea y el CH 96 han resultado más simples, dado el carácter inter partes con que se aplican estas disposiciones. Este carácter inter partes justifica además la doble normativa, pues puede establecerse, como efectivamente se ha hecho, un régimen privilegiado de eficacia extraterritorial entre los Estados miembros de la Unión Europea. El tenor literal del art. 52.2 CH 96, que alude, como se ha visto, al lugar de residencia habitual del niño a efectos de determinar la preferencia aplicativa de un instrumento internacional u otro, no era sin embargo claro en relación con este propósito. La letra de art. 61.b) del Reglamento 2201/2003, ahora art. 97.1.b) del Reglamento 2019/1111, sí lo es, pues se refiere, en lo que respecta al reconocimiento y ejecución, a que se trate de una decisión dictada por un órgano jurisdiccional de otro Estado miembro, aun cuando el menor afectado tenga su residencia habitual en un Estado que sea parte contratante del Convenio y en el que no se aplique el Reglamento.

23. Para evitar cualquier duda al respecto, y preservar la aplicación preferente de las normas sobre reconocimiento y ejecución del Reglamento frente al CH 96, independientemente del lugar de residencia habitual del menor, los Estados miembros de la Unión Europea realizaron una declaración en el momento de vincularse por el CH 96, en el siguiente sentido: "En los artículos 23, 26 y 52 del Convenio se permite a las Partes Contratantes cierto grado de flexibilidad para aplicar un régimen sencillo y rápido de reconocimiento y ejecución de las sentencias. Las normas comunitarias prevén un sistema de reconocimiento y ejecución que es como mínimo tan favorable como las normas que establece el Convenio. En consecuencia, una sentencia dictada en un órgano jurisdiccional de un Estado miembro de la Unión Europea en relación con una materia contemplada en el Convenio será reconocida y ejecutada en [...], aplicando las normas internas correspondientes del Derecho comunitario"'33. Se trató de una declaración acorde con el espíritu de los Convenios de la Conferencia de La Haya de no interferir en las relaciones que puedan establecer dos Estados parte, o en este caso un grupo de Estados parte, para me-

\footnotetext{
${ }^{32} \mathrm{Al}$ respecto vid. P. LAGARDE, Informe explicativo relativo al Convenio de La Haya de 19 de octubre de 1996 relativo a la competencia, la ley aplicable, el reconocimiento, la ejecución y la cooperación en materia de responsabilidad parental y de medidas de protección de los niños, Oficina Permanente de la Conferencia de La Haya de Derecho Internacional Privado, https://assets.hcch.net/docs/aa132b31-385d-4a66-b8d9-2d362053ed75.pdf, pp. 71-72; A. BorRÁs, "La cláusula de compatibilidad del art. 52.2 del Convenio de La Haya de 1996 y los instrumentos comunitarios", Nuevas fronteras del derecho de la Unión Europea. Liber amicorum J.L. Iglesias Buhigues, Valencia, Tirant lo Blanch, 2012, pp. 194 y ss.

${ }_{33}$ Art. 2 de la Decisión del Consejo 19 de diciembre de 2002 y Art. 2 de la Decisión del Consejo de 5 de junio de 2008 (Vid. supra epígrafe II).
} 
jorar entre ellos los mecanismos de funcionamiento del convenio internacional, siempre que no afecte a las relaciones con otros Estados parte del mismo.

24. En relación con las normas sobre cooperación de autoridades nada se ha previsto expresamente en los artículos que venimos analizando. No obstante, la aplicación con carácter inter partes de esta normativa, referida a la cooperación o ayuda que se prestan las autoridades de los Estados en beneficio del interés superior del menor, debe llevarnos a la misma conclusión ya vista que a propósito de la eficacia extraterritorial de resoluciones. Se puede decir que en el sector de la cooperación de autoridades la unificación con un pretendido carácter universal se articula bien con la de carácter regional, pues permite profundizar en el nivel de cooperación que pueden desarrollar Estados más próximos ${ }^{34}$.

\section{Las relaciones entre el Reglamento 2019/1111 y el CH 96 en el sector de la competencia judicial internacional}

\section{La aplicación del Reglamento 2019/1111 o del CH 96 en función del lugar de residencia habitual del menor. Consecuencias}

25. Como hemos visto, el lugar de residencia habitual del menor se convierte en un elemento fundamental de cara a la correcta articulación de estos dos instrumentos internacionales en el sector de la competencia judicial internacional, ya que si se encuentra en un Estado miembro de la Unión Europea se aplicarán las normas del Reglamento 2019/1111, con las salvedades que en el propio art. 97.2 se establecen, y si se encuentra en el territorio de un Estado parte del CH 96, que no es miembro de la Unión Europea, se aplicarán las normas del Convenio. Obviamente, y tal como ya sabemos, serán son sólo los órganos jurisdiccionales y autoridades de los Estados miembros de la Unión Europea los que tendrán que plantearse esta disyuntiva, dado que son estos Estados los que participan en ambos instrumentos ${ }^{35}$.

26. La opción por las normas de competencia judicial internacional del Reglamento 2019/1111 o del CH 96 tiene realmente una trascendencia limitada. Vamos a comparar las normas de competencia judicial internacional de estos dos instrumentos internacionales, siguiendo el orden en que aparecen en el Reglamento 2019/1111, para comprobar que en realidad son muy similares ${ }^{36}$. En esta comparación haremos algunas referencias a cuándo deben aplicarse unas u otras, sin perjuicio de que sigamos profundizando sobre esta cuestión en los siguientes epígrafes.

27. En el art. 7 del Reglamento 2019/1111 y en el art. 5 del CH 96 se recoge la misma regla general de competencia judicial internacional, que atiende al lugar de residencia habitual del menor. Las tribunales y autoridades de los Estados miembros, cuando se declaren competentes en base a la residencia habitual del menor, tendrán que hacerlo aplicando el art. 7 del Reglamento, pues es la residencia en un Estado miembro, como sabemos, lo que determina la preferencia aplicativa del Reglamento. En ambos Instrumentos se regula de forma diferente no obstante la incidencia que puede tener el cambio de residencia habitual del menor durante el procedimiento, lo que puede plantear algunos problemas de articulación, tal como veremos después.

${ }^{34}$ De hecho, el art. 39 CH 96 se refiere expresamente a la posibilidad de concluir acuerdos entre Estados contratantes, para mejorar la aplicación del Capítulo V "Cooperación” en sus relaciones recíprocas.

${ }^{35}$ En el marco del Reglamento 2019/1111 se utiliza el término órgano jurisdiccional en sentido amplio, para referirse a cualquier autoridad de cualquier Estado miembro con competencia en las materias que entran en el ámbito de aplicación del Reglamento (art. 2.2.1). El CH 96 prefiere usar la noción de autoridades, que también debe entenderse en sentido amplio, para comprender autoridades judiciales o administrativas (art. 5).

${ }^{36}$ De hecho, fue bastante cuestionada la conveniencia de que a nivel europeo se regulase la competencia judicial internacional en materia de responsabilidad parental, pues se contaba ya con las normas del CH 96. Al respecto, vid. TH.M DE BoER, "Jurisdiction and enforcement in international family law: a labyrinth of European and international legislation, Netherlands international law review, Vol. 49, No 3, 2002, pp. 335 y ss. 
28. En el art. 8 del Reglamento 2019/1111 se contempla un foro especial para la modificación de una previa resolución sobre derecho de visita, cuando haya un traslado de residencia habitual del menor dentro de la legalidad entre Estados miembros. Este precepto no tiene equivalente en el $\mathrm{CH}$ 96, por lo que en los cambios de residencia habitual del menor entre Estados miembros y Estados parte exclusivamente de este Convenio, el titular del derecho de visita no dispondrá de esta posibilidad.

29. El art. 9 del Reglamento 2019/1111 se ocupa de la competencia judicial internacional en caso de traslado o retención ilícita de un menor entre Estados miembros, tratando de limitar la competencia de los órganos jurisdiccionales del Estado miembro de la nueva residencia habitual, para desincentivar la sustracción internacional de menores. Se trata de una norma sustancialmente equivalente a la prevista en el art. art. $7 \mathrm{CH}$ 96, que sería la aplicable en las relaciones con Estados parte exclusivamente de este Convenio.

30. El art. 10 del Reglamento 2019/1111 permite la elección de tribunal competente. El art. 10 CH 96 también lo permite, pero de forma más limitada, pues se prevé únicamente para que conozcan de la cuestión de responsabilidad parental los mismos tribunales que conocen del divorcio, la separación o anulación del matrimonio de los padres. Se aplicará el primer precepto cuando el menor reside en un Estado miembro y la elección se produce en favor de los órganos jurisdiccionales de otro Estado miembro, y las condiciones más restrictivas del segundo cuando el niño reside en un Estado parte del CH 96 y la elección se produce en favor de los órganos jurisdiccionales de un Estado miembro o a la inversa. Sobre estos preceptos volveremos más adelante ${ }^{37}$.

31. Los arts. 11 del Reglamento 2019/1111 y 6 del CH 96 se refieren a la competencia basada en la presencia del menor cuando no pueda determinarse su residencia habitual, señalando que también se aplicarán a los menores refugiados y desplazados internacionalmente. Se trata de dos preceptos muy similares, con alguna variación en cuanto a la posibilidad de elección de tribunal, sobre la que ya hemos dicho que en el Reglamento 2019/1111 se permite en términos más amplios. La aplicación de uno u otro en el caso de los menores refugiados y desplazados dependerá de dónde tenían con anterioridad su residencia habitual, como tendremos oportunidad de reflejar seguidamente.

32. Los arts. 12 y 13 del Reglamento 2019/1111 se refieren a la remisión a un órgano jurisdiccional mejor situado para conocer del fondo del asunto, al igual que los arts. 8 y $9 \mathrm{CH} 96$. La norma europea ofrece algunas precisiones adicionales con respecto al $\mathrm{CH} 96$, sobre cuándo puede considerarse que el órgano jurisdiccional de otro Estado miembro está efectivamente mejor situado para conocer del asunto. Pues bien, la aplicación de unos preceptos u otros dependerá de si se activa este mecanismo de remisión entre Estados miembros o entre un Estado miembro y un Estado parte exclusivamente del CH 96, tal como veremos en un epígrafe posterior ${ }^{38}$.

33. Por otra parte, el CH 96 presenta, como peculiaridad, el hecho de que permite en su art. 55 que cualquier Estado pueda reservarse, conforme al art. 60, la competencia de sus autoridades para adoptar medidas de protección de los bienes de un niño situados en su territorio. España lo ha hecho. El art. 55 podrá aplicarse cuando el niño tenga su residencia habitual en un Estado parte exclusivamente del CH 96. Cuando el niño resida en un Estado miembro no será posible, dado que prima el Reglamento 2019/1111, que no lo permite ${ }^{39}$.

\footnotetext{
${ }^{37}$ Vid. infra epígrafe IV.3.A)

38 Vid. infra epígrafe IV.3.B)

${ }^{39}$ Entre las peculiaridades que presentan estos Instrumentos internacionales habría que mencionar también el art. 16 del Reglamento 2019/1111. Se trata de un nuevo precepto que permite, por una parte, que un órgano jurisdiccional de un Estado miembro conozca con carácter incidental de una cuestión de responsabilidad parental, a pesar de carecer de competencia con arreglo al Reglamento; y por otra, que un órgano jurisdiccional de un Estado miembro pueda decidir sobre la validez de un acto jurídico que vaya a realizarse en nombre del menor en un procedimiento sucesorio, a pesar también de carecer de competencia con arreglo al Reglamento. Esta norma entendemos que no podría aplicarse cuando el niño resida en un Estado parte exclusivamente del CH 96, dado que este Convenio no contiene una norma similar. En ambos instrumentos internacionales sí se regula la competencia para adoptar medidas provisionales, incluidas las cautelares, en caso de urgencia, de forma similar, atendiendo a la presencia del menor o de sus bienes (art. 15 del Reglamento 2019/1111 y arts. 11-12 CH 96).
} 
34. Un aspecto que venía suscitando dudas y que en el Reglamento 2019/1111 no se ha resuelto claramente, en nuestra opinión, es el relativo a qué normas de competencia judicial internacional deben aplicar los Estados miembros cuando el menor reside en un tercer Estado, que no es parte del $\mathrm{CH} 96^{40}$. Se trata de un problema de entidad limitada, por lo siguiente: son pocas las normas de competencia judicial internacional de estos instrumentos susceptibles de aplicarse en tales situaciones; y las que lo son, pueden conducir a un mismo resultado.

35. Entre esas normas se encuentran las relativas a menores refugiados y desplazados internacionalmente, de los arts. 11 del Reglamento 2019/1111 y 6 CH 96. En este caso vemos que sí se ha introducido una aclaración en el Considerando 25 del Preámbulo del Reglamento, en la que se justifica la aplicación preferente de las normas de competencia judicial internacional del $\mathrm{CH}$ 96, tratándose de menores desplazados desde terceros Estados, con una referencia al art. 52.2 del CH 96, al que ya anteriormente hemos tenido oportunidad de referirnos. En cualquier caso, tanto el Reglamento 2019/1111 como el CH 96 ofrecen la misma solución, al referirse a los órganos jurisdiccionales y autoridades del lugar donde está el menor.

36. Entre las normas susceptibles de aplicarse con respecto a menores residentes en terceros Estados se encontraría también el art. 10 del Reglamento 2019/1111 sobre acuerdos de elección de foro. El art. 12.4 del Reglamento 2201/2003 se refiere a la posibilidad de acudir a los órganos jurisdiccionales de un Estado miembro cuando el menor tenga su residencia habitual en un tercer Estado, que no sea parte del CH 96. Pero este apartado se ha suprimido del art. 10 del nuevo Reglamento, sin que en los documentos de trabajo que se han publicado sobre su proceso de negociación hayamos encontrado alguna explicación al respecto. En este caso, que la aplicación preferente del CH 96 pudiera ser un obstáculo para acudir a los órganos jurisdiccionales de un Estados miembro en base al art. 10 del Reglamento 2019/1111, cuando la realidad es que el CH 96 ni siquiera contempla la posibilidad que estamos analizando - en su art. 10 regula estos acuerdos, refiriéndose únicamente a niños con residencia habitual en un Estado contratante-, pensamos que no tendría mucho sentido. Hay que tener presente el carácter general del Reglamento 2219/1111, que sólo reconoce un papel residual a las normas nacionales de competencia judicial internacional (art. 14), y que en este caso no se estaría perjudicando la competencia de los órganos jurisdiccionales de un Estado parte del CH 96.

\section{El foro de la residencia habitual del menor y su relación con la aplicación del Reglamento 2019/1111 o del CH 96}

37. Como hemos tenido oportunidad de señalar, en el art. 7 del Reglamento 2019/1111 y en el art. 5 del CH 96 se recoge la misma regla general de competencia judicial internacional, que atiende al lugar de residencia habitual del menor. No obstante, como también decíamos con anterioridad, en ambos preceptos se regula de forma diferente la incidencia que puede tener el cambio de residencia habitual del menor durante el procedimiento. El art. 7.1 del Reglamento 2019/1111 dispone que los órganos jurisdiccionales de un Estado miembro serán competentes en materia de responsabilidad parental respecto de un menor que resida habitualmente en dicho Estado miembro, en el momento en que se acuda al órgano jurisdiccional. El art. $5 \mathrm{CH} 96$ dispone igualmente, en su aptdo. $1^{\circ}$, que las autoridades del Estado contratante de la residencia habitual del niño serán competentes para adoptar las medidas para la protección de su persona o de sus bienes, pero añade a continuación, en su aptdo. $2^{\circ}$, que en caso de cambio de la residencia habitual del niño a otro Estado contratante serán competentes las autoridades del Estado de la nueva residencia habitual menor.

${ }^{40} \mathrm{Al}$ respecto vid. A.L. Calvo Caravaca y J. Carrascosa González, Derecho internacional privado, Vol. II, $18^{\mathrm{a}}$ ed., Comares, Granada, 2018, pp. 431-432; J.C. Fernández Rozas y S. SÁnchez Lorenzo, Derecho internacional privado, 10ª ed., Civitas, Thomson Reuters, 2018, pp. 395-396; P. McEleavy, "The 1996 Hague Convention and the European Union: connection and disconnection", A commitment to private international law. Essays in honour of H. Van Loon, Intersentia, Cambridge - Antwerp - Portland, 2013, p. 375. 
38. Esta particularidad que presenta el CH 96 afecta a la articulación entre instrumentos internacionales. Como se señaló durante el proceso de revisión del Reglamento 2201/2003, se estaban planteando problemas en relación con niños que trasladaban su residencia habitual desde un Estado miembro de la Unión Europea a un Estado parte exclusivamente en el CH 96 (ej. de Alemania a Suiza), pues con arreglo al Reglamento no se contempla que los tribunales ante los que ya se ha iniciado el procedimiento pierdan su competencia en favor de los del lugar de la nueva residencia habitual, en virtud del principio de la perpetuatio fori. Con arreglo al $\mathrm{CH} 96$ y a su art. 5 pasan a ser competentes, como se ha visto, los tribunales del lugar de nueva residencia habitual ${ }^{41}$. Tengamos presente, para evidenciar el problema a nivel de articulación de instrumentos internacionales que se plantea, que este traslado determinaría que pasaran a aplicarse las normas de competencia judicial internacional del CH 96.

39. En respuesta al problema detectado durante los trabajos de revisión del Reglamento 2201/2003, hemos de señalar que en la Propuesta inicial presentada por la Comisión se incorporó una reforma del foro general de competencia ${ }^{42}$, para alinearlo con el $\mathrm{CH} 96 . \mathrm{El}$ art. 7 de la Propuesta decía que cuando un menor cambiase legalmente de residencia de un Estado miembro a otro y adquiriese una nueva residencia habitual en este último, serían competentes las autoridades del Estado miembro de la nueva residencia habitual. Cierto es que en la Propuesta de la Comisión se contemplaba únicamente el traslado de residencia entre Estados miembros, pero se trataba de una modificación que venía a poner fin al principio de la perpetuatio fori, favoreciendo una mejor articulación con el CH 96.

40. En la Primera Resolución del Parlamento Europeo se introdujeron algunas limitaciones. En principio se mantenía el criterio del cambio en la competencia judicial internacional, a menos que las partes acordasen que seguirían siendo competentes las autoridades del Estado miembro en el que el menor residía habitualmente hasta entonces ${ }^{43}$. Además se proponía un nuevo apartado (art. 7.1.bis) para referirse específicamente a las causas pendientes en materia de derechos de custodia y visita, señalando que seguirían siendo competentes las autoridades del Estado miembro de origen hasta la conclusión del proceso, a menos que las partes acordasen que se debía poner fin al mismo. En la justificación de este nuevo apartado se decía que se trataba de evitar con ello que se organizara el traslado de un niño con el fin de escapar a una decisión desfavorable ${ }^{44}$. No obstante, en el documento del Consejo relativo a la orientación general sobre la Propuesta de Reglamento, se decidió abandonar este cambio, con una redacción que volvía al originario precepto del Reglamento 2201/2003 ${ }^{45}$. Y esta última versión, con algún retoque de redacción, es la que se ha mantenido en el Reglamento 2019/1111.

41. Esta opción final nos debe llevar a reflexionar sobre el concepto de residencia habitual y las dificultades que se han planteado en su determinación, porque quizás puedan ser la causa. Tradicionalmente, el concepto de residencia habitual no se ha definido en los instrumentos internacionales para preservar su carácter fáctico ${ }^{46}$. Se trata con ello de escapar de definiciones legales, que podrían variar de

${ }^{41}$ Study on the assessment of Regulation (EC) Núm. 2201/2003 and the policy options for its amendment, final report, evaluation, op. cit., p. 15; H. VAn Loon, "The Brussels IIa Regulation: towards a review?”, op. cit., p. 192; Th.M. DE BoER, "What we should not expect from a recast of the Brussels IIbis Regulation”, op. cit., p. 16.

42 Vid. supra nota 5.

${ }^{43}$ Esta posibilidad ya se contemplaba en la Propuesta de la Comisión, pero en el Preámbulo del Reglamento (Considerando 15).

${ }^{44}$ Vid. supra nota 10.

45 Bruselas, 30 de noviembre de 2018, 14784/18, JUSTCIV 292, https://eur-lex.europa.eu/legal-content/ES/TXT/PDF/?uri=CONSIL:ST_14784_2018_INIT\&from=EN

${ }^{46}$ El Reglamento (CE) $n^{\circ}$ 593/2008 del Parlamento Europeo y del Consejo, de 17 de junio de 2008, sobre la ley aplicable a las obligaciones contractuales (Roma I), en su art. 19, y el Reglamento (CE) $n^{\circ}$ 864/2007 del Parlamento Europeo y del Consejo, de 11 de julio de 2007, relativo a la ley aplicable a las obligaciones extracontractuales (Roma II), en su art. 23, sí entran a concretar el lugar de residencia habitual, pero debido, al menos así lo entendemos, a que se está usando el concepto de residencia habitual en un contexto en que los actores principales van a ser personas jurídicas o personas físicas que actúan en su calidad de comerciantes. El Reglamento (UE) $n^{\circ}$ 650/2012 del Parlamento Europeo y del Consejo, de 4 de julio de 2012, relativo a la competencia, la ley aplicable, el reconocimiento y la ejecución de las resoluciones, a la aceptación y la ejecución de los documentos públicos en materia de sucesiones mortis causa y a la creación de un certificado sucesorio europeo, no define el concepto en su articulado, pero sí ofrece directrices en su Preámbulo para concretarlo (Considerandos 23 y 24). 
un ordenamiento jurídico a otro, con las dificultades que ello plantearía. En circunstancias normales, la falta de definición del concepto de residencia habitual no tiene por qué plantear grandes problemas. Sin embargo, la práctica ya se ha encargado de demostrarnos que se dan situaciones en las que surgen dudas, y de hecho, el TJUE ha tenido que pronunciarse en diversas ocasiones sobre el concepto de residencia habitual en el marco del Reglamento 2201/2003 ${ }^{47}$.

42. En la Sentencia del TJCE de 2 de abril de 2009, A, as. 523/0748, se sentaron las notas configuradoras del concepto de residencia habitual. Concretamente, el TJCE señaló que la mera presencia física del menor en un Estado miembro no bastaba para determinar su residencia habitual (p. 33), pues además debían tenerse en cuenta otros factores que indicasen una cierta integración en un entorno familiar y social (p. 38). En la Sentencia del TJUE de 22 de diciembre de 2010, Barbara Mercredi y Richard Chaffe, as. 497/10 $\mathrm{PPU}^{49}$, se planteó como peculiaridad, frente a la anterior, que era necesario determinar la residencia habitual de un menor lactante, para lo que el TJUE precisó que los indicios o factores de integración debían concretarse atendiendo a las circunstancias de la madre, que era quien tenía el menor a su cargo (p. 56). La Sentencia del TJUE de 9 de octubre de 2014, C y M, as. 376/14 PPU, ${ }^{50}$ se enfrentó a la peculiaridad de tener que determinar el lugar de residencia habitual en el marco de un proceso que aún no había terminado, pues se había trasladado al menor a otro Estado miembro en virtud de una resolución judicial, que era ejecutiva con carácter provisional, y que fue posteriormente revocada. En la Sentencia del TJUE de 15 de febrero de 2017 , W, V y X, as. 499/15 $5^{51}$ se planteó, a diferencia de la anterior, dónde estaba el lugar de residencia habitual del menor a efectos de modificar las medidas que ya habían sido adoptadas en otro proceso, que había concluido. Más recientemente, las dudas han derivado hacía la relevancia que debe concederse a la intención de los progenitores para determinar el lugar de residencia habitual de menores. En este sentido pueden citarse las Sentencia del TJUE de 8 de junio de 2017, OL y PQ, as. 111/17 PPU ${ }^{52}$; de 28 de junio de 2018, HR, as. 512/17 $7^{53}$; y de 17 de octubre de 2018, UD y XB, as. 393/18 PPU $^{54}$.

43. En este contexto, la modificación que se proponía para el foro general de competencia judicial internacional, en el sentido de abandonar el principio de la perpetuatio fori, podría haber supuesto un factor de inseguridad jurídica adiciona $1^{55}$. Se da además la circunstancia de que en el Reglamento 2201/2003, al igual que ahora en el Reglamento 2019/1111, ya se dispone de un mecanismo flexibilizador, que permitiría dar respuesta a los inconvenientes asociados al principio de la perpetuatio fori ${ }^{56}$.

${ }^{47}$ En este contexto de dificultades es lógico que haya propuestas para tratar de concretar el concepto de residencia habitual, Vid. L.A. Pérez Marín, "Propuesta de un concepto europeo de residencia habitual en derecho de familia internacional", Anuario Español de Derecho Internacional Privado, t. XVIII, 2018, pp. 469 y ss.

${ }^{48}$ ECLI:EU:C:2009:225, nota de E. Rodríguez PINEAU, Revista española de Derecho internacional, Vol. LXI, $\mathrm{n}^{\circ}$ 1, 2009, pp. 197 y ss.

${ }^{49}$ ECLI:EU:C:2010:829, nota de S. Álvarez GonzÁlez, Revista Española de Derecho Internacional, Vol. LXII, nº 2, 2010, pp. 251 y ss.

${ }^{50}$ ECLI:EU:C:2014:2268

${ }^{51}$ ECLI:EU:C:2017:118. Sobre esta sentencia vid. S. ÁlvAREz GonZÁLEZ, "Competencia judicial internacional para la modificación de sentencia en materia de responsabilidad parental y de obligaciones alimenticias. Sentencia de 15 de febrero de 2017, asunto C-499/15: W y V”, La Ley Unión Europea, N 47, 2017, pp. 1 y ss.

${ }^{52}$ ECLI:EU:C:2017:436.

${ }^{53}$ ECLI:EU:C:2018:513.

${ }^{54}$ ECLI:EU:C:2018:835. Sobre esta sentencia vid. L.A. PÉrez Martín, "Residencia habitual de los menores y vulneración de derechos fundamentales. Sentencia del Tribunal de Justicia de 17 de octubre de 2018, asunto C-393/18, PPU", La Ley Unión Europea, $\mathrm{n}^{\circ}$ 66, 2019; B. CAMPUZAno Díaz, "Una nueva Sentencia del TJUE sobre el concepto de residencia habitual en el marco del Reglamento 2201/2003: Sentencia de 17 de octubre de 2018, UD y XB, As. 393/18 PPU”, Cuadernos de Derecho Transnacional, Vol. 11, N 2, 2019, pp. 451 y ss.

${ }^{55}$ Cierto es que contamos ya, como se ha visto, con una abundante jurisprudencia del TJUE sobre el concepto de residencia habitual, donde se ofrece una serie de factores de los que deducir el lugar de residencia habitual del menor. Pero tal como se ha puesto de manifiesto, dichos factores se prestan a ser aplicados de forma diferentes por los Estados miembros. Vid. T. KRUGER, "Chapter 2. Finding a habitual residence", I. Viarengo y F.C. Villata (eds.), Planning the future of cross-border families: a path through coordination. Final study, pp. 79 y ss, consultado en: EUFam's Project, http://www.eufams.unimi.it/project/.

${ }^{56}$ Los inconvenientes se vinculan con el hecho de que la perpetuatio fori puede llevar al conocimiento del asunto por un tribunal que presenta ya una escasa conexión con el menor, que concluirá con una resolución que puede plantear problemas 
Concretamente, en el art. 15 del Reglamento 2201/2003, ahora art. 12 del Reglamento 2019/1111, se prevé que el órgano jurisdiccional de un Estado miembro competente para conocer del fondo del asunto, pueda remitirlo al órgano jurisdiccional de otro Estado miembro si considera que tiene una estrecha vinculación con el asunto y puede valorar mejor el interés superior del menor. Entre las circunstancias en que se presume dicha vinculación se menciona que ese otro Estado miembro se haya convertido en el de la residencia habitual del menor después de la presentación de la demanda.

44. La opción por la seguridad jurídica en la aplicación del foro general del art. 7 del Reglamento $2019 / 1111$, flexibilizada en la forma en que acabamos de señalar ${ }^{57}$, deja no obstante sin resolver el problema de articulación con el CH 96, que se había puesto de manifiesto durante los trabajos preparatorios del Reglamento. En este problema puede influir además el modo de interpretar el concepto de residencia habitual en los Estados parte exclusivamente del $\mathrm{CH}$ 96, ya que sus autoridades no están vinculadas por la jurisprudencia del TJUE y pueden dar mayor importancia a otros criterios, como por ejemplo, la referida intención de los progenitores ${ }^{58}$. Se puede decir por tanto que entre la opción por mantener la solución que ya se recogía en el Reglamento 2001/2003 u optar por una mejor articulación con el CH 96, la Unión Europea se ha inclinado por lo primero. El art. 13 del CH 96 recoge una regla para evitar la dualidad de procedimientos, que podría servir para dar respuesta al problema que aquí se plantea, pero presenta como inconveniente el hecho de que se aplica sobre la base de que los tribunales de los dos Estados contratantes ante los que está pendiente el asunto son competentes con arreglo al Convenio, y el tribunal de la Unión Europea ya no lo sería ${ }^{59}$. Un reparo similar se podría hacer al mecanismo de transferencia de la competencia previsto en los arts. 8 y $9 \mathrm{CH} 96$, si bien una interpretación de estos preceptos que tuviera en cuenta la conveniencia de una buena articulación entre instrumentos internacionales, podría servir para generar un marco de colaboración y ofrecer así una respuesta adecuada al interés superior del menor ${ }^{60}$.

de reconocimiento en el país donde ya se encuentra el menor. Vid. Vid. Study on the assessment of Regulation (EC) Num. 2201/2003 and the policy options for its amendment, final report, analytical annexes, op. cit., pp. 29-30; TH.M. DE BOER, "What we should not expect from a recast of the Brussels IIbis Regulation”, op. cit., pp. 15-17.

${ }^{57}$ A ello se refiere el Considerando 21 del Reglamento 2019/1111: "Cuando no haya aún procedimientos en curso en materia de responsabilidad parental y la residencia habitual del menor cambie a raiz de un traslado lícito del menor, la competencia debe seguirle con el fin de mantener la proximidad. Para los procedimientos que ya estén en curso, la seguridad jurídica y la eficiencia de la justicia justifican el mantenimiento de la competencia hasta que los procedimientos hayan desembocado en una resolución definitiva o hayan concluido de otra forma. El órgano jurisdiccional en el que se esté sustanciando el procedimiento debe, no obstante, estar facultado en determinadas circunstancias para transferir la competencia al Estado miembro en el que el menor esté viviendo a raíz de un traslado lícito".

${ }^{58}$ En este sentido podemos señalar que el concepto de residencia habitual ha sido ampliamente analizado a propósito del Convenio de La Haya de 25 de octubre de 1980 sobre los aspectos civiles de la sustracción internacional de menores, donde, al igual que en el marco del Reglamento 2201/2003, juega un papel fundamental a efectos de determinar que se ha producido un traslado o retención ilícitos entre Estados parte. Pues bien, se observan varias posturas en la jurisprudencia de los distintos Estados parte a la hora de precisar el lugar de residencia habitual del menor, sin que todas ellas sean coincidentes con la jurisprudencia del TJUE: una primera, que atiende al menor y a su centro de vida, considerando aspectos de carácter fáctico; una segunda, que atiende a la intención de los progenitores que cuidan del menor, considerando que son los que tienen derecho a decidir su lugar de residencia; y una tercera, denominada híbrida, que combina los dos anteriores, de forma que mantiene el énfasis en las circunstancias fácticas del menor, pero considerando también las intenciones de los progenitores, Al respecto vid. Ma .C. Cheliz INGLÉs, La sustracción internacional de menores y la mediación. Retos y vías prácticas de solución, Tirant lo Blanch, Valencia, 2019, págs. 46 y ss. En relación con la influencia que puede ejercer en el $\mathrm{CH}$ 96, la interpretación que del concepto de residencia habitual se hace en relación con el secuestro internacional de menores, se ha subrayado la necesidad de tener en cuenta los distintos objetos de estos Convenios, vid. Manual práctico sobre funcionamiento del Convenio de La Haya de 1996 sobre protección de niños, publicado por la Conferencia de La Haya de Derecho internacional privado, 2014, pág. 178 (se puede consultar en la siguiente dirección de Internet: https://assets.hcch.net/docs/68be6d4e-f4b8-4a8e-b041-faaa17efb050.pdf). No obstante, hay autores que señalan que es muy probable que esa interpretación sí ejerza influencia, N. LOWE y M. NICHOLLS, International Movement of Children. Law, Practice and Procedure, 2nd ed., Lexis Nexis, Bristol, 2016, pág. 93.

${ }^{59}$ T. Kruger y L. SAmyn, "Brussels II bis: successes and suggested improvements", op. cit., p. 153.

60 "En el Manual práctico sobre funcionamiento del Convenio de La Haya de 1996 sobre protección de niños, publicado por la Conferencia de La Haya de Derecho internacional privado, op. cit., p. 41, se sugiere su utilización. 


\section{Las reglas especiales de coordinación}

45. En el art. 97 del Reglamento 2019/1111 se ha tratado de mejorar la articulación con el CH 96, mediante un nuevo apartado que dispone lo siguiente: "2. No obstante lo dispuesto en el apartado 1, a) si las partes han convenido en la competencia de un órgano jurisdiccional de un Estado parte del Convenio de La Haya de 1996 en el que no se aplique el presente Reglamento, se aplicará el artículo 10 de dicho Convenio; b) con respecto a la transferencia de competencia entre un órgano jurisdiccional de un Estado miembro y un órgano jurisdiccional de un Estado parte del Convenio de La Haya de 1996 en el que no se aplique el presente Reglamento, se aplicarán los artículos 8 y 9 de dicho Convenio; c) cuando un procedimiento de responsabilidad parental se halle pendiente ante un órgano jurisdiccional de un Estado parte del Convenio de La Haya de 1996 en el que no se aplique el presente Reglamento en el momento en que un órgano jurisdiccional de un Estado miembro esté conociendo de un litigio relativo al mismo menor y con el mismo objeto, se aplicará el artículo 13 de dicho Convenio”.

46. La incorporación de este nuevo apartado en la Propuesta de la Comisión ${ }^{61}$, que se mantuvo con algunos retoques de redacción en el Reglamento definitivamente aprobado, respondió a un problema detectado durante los trabajos preparatorios. En concreto, se planteó qué instrumento internacional debía aplicarse para transferir el conocimiento del asunto a un tercer Estado mejor situado para conocer del mismo, cuando el menor tenía su residencia habitual en un Estado miembro. La dificultad surgía porque el art. 15 del Reglamento 2201/2003 sólo permitía transferir el conocimiento del asunto a otro Estado miembro, y aunque los arts. 8 y 9 CH 96 sí permitían hacerlo a un tercer Estado parte de este instrumento internacional, debía aplicarse el Reglamento en virtud del art. 61, por tener el menor su residencia habitual en un Estado miembro ${ }^{62}$. Un problema similar podía plantearse para reconocer efectos al acuerdo por el que las partes decidían someter el conocimiento del asunto a los tribunales de un tercer Estado parte del CH 96 o con la situación de litispendencia que se ha podido generar con los tribunales de uno de estos Estados. El art. 97.2 del Reglamento 2019/1111 viene ahora a dar ahora respuesta a estas tres situaciones.

\section{A) Cuando las partes han convenido en la competencia de un órgano jurisdiccional de un Estado parte del CH 96}

47. El art. 97.2.a) dispone que si las partes han convenido en la competencia de un órgano jurisdiccional de un Estado parte del Convenio de La Haya de 1996 en el que no se aplique el presente Reglamento, se aplicará el artículo 10 de dicho Convenio. Con esta nueva disposición se trata de proteger la voluntad de las partes, pues podrá aplicarse el art. $10 \mathrm{CH} 96$ a pesar de que el menor resida habitualmente en un Estado miembro, evitándose los problemas a los que anteriormente nos referíamos.

48. El art. $10 \mathrm{CH} 96$ se refiere a las autoridades de un Estado contratante, para señalar que en el ejercicio de su competencia para conocer de una demanda de divorcio, separación o anulación del matrimonio, podrán adoptar medidas de protección con respecto a la persona o bienes del niño con residencia habitual en otro Estado contratante, si la ley de su Estado lo permite, siempre que se den las circunstancias siguientes ${ }^{63}$ : uno de los padres resida habitualmente en dicho Estado en el momento de iniciarse el

61 Vid. supra nota 5.

62 Study on the assessment of Regulation (EC) Num. 2201/2003 and the policy options for its amendment, final report, evaluation, op. cit., p. 15. A este problema también se habían referido T. KRUGER y L. SAMYN, "Brussels II bis: successes and suggested improvements", op. cit., pp. 152-154; M. ZuPAN, "Scope of application, definitions and relations to other instruments (Articles 1, 2 and 59-62)", C. Honorati (ed.), Jurisdiction in matrimonial matters, parental responsibility and international abduction. A handbook on the application of Brussels IIa Regulation in national courts, Giappichelli editore, Torino, 2017, p. 33.

${ }^{63}$ La referencia a que la ley del Estado contratante lo permita lleva a que el art. $10 \mathrm{CH} 96$ tenga un carácter más restrictivo que la norma europea. El art. 12 del Reglamento 2201/2003, ahora art. 10 Reglamento 2019/1111, otorga competencia por si sólo a los tribunales que conocen del divorcio para decidir sobre las cuestiones de responsabilidad parental, en base al acuerdo de los titulares de la responsabilidad parental, independientemente de si a estos les correspondiera con arreglo al derecho interno, C. 
procedimiento; uno de ellos tenga la responsabilidad parental respecto al niño; que la competencia de estas autoridades haya sido aceptada por los padres y cualquier otra persona que tenga la responsabilidad parental; y que esta competencia responda al interés superior del niño. Cumpliéndose estos requisitos, la competencia que otorga el art. $10 \mathrm{CH} 96$ se verá reconocida en todos los Estados parte del Convenio.

49. Como ya hemos tenido oportunidad de señalar, entre el Reglamento 2019/1111 y el CH 96 no existe una absoluta simetría de soluciones. En la Unión Europea se reconoce la posibilidad de elegir el tribunal competente en términos más amplios. El art. 12 del Reglamento 2201/2003 se refiere en sus aptdos. $1^{\circ}$ y $2^{\circ}$ al supuesto contemplado en el $\mathrm{CH} 96$, pero abre a continuación en su aptdo. $3^{\circ}$ la posibilidad de prorrogar la competencia en otros supuestos, que no tienen por qué estar conectados con la causa matrimonial. El concepto de responsabilidad parental es muy amplio, cubre numerosas medidas relacionadas con la protección de los menores, y puede ser oportuna una cierta flexibilización de las normas de competencia judicial internacional, mediante la posibilidad de elegir el tribunal ${ }^{64}$. El Reglamento 2019/1111 ha optado por eliminar la diferenciación de supuestos que se hace en el Reglamento 2201/2003, refiriéndose en su art. 10, con carácter general, a la posibilidad de elegir el órgano jurisdiccional competente, sin que con ello haya querido dotar al precepto de un carácter más restrictivo, tal como se deja claro en el Preámbulo del Reglamento (Considerando 23).

50. En consecuencia, en el art. 10 del Reglamento 2019/1111 se unifican los requisitos para que pueda realizarse una válida elección del órgano jurisdiccional competente, que son los siguientes: por una parte, que el menor esté estrechamente vinculado a ese Estado miembro, por alguno de los factores que se enumeran en el propio precepto (art. 10.1.a); y por otra, que la elección por las partes o cualquier otra persona con responsabilidad parental, se haga en el momento y en la forma en que se determina en este precepto (art. 10.1.b en conexión con el art. 10.2). Se añade, como no podía ser de otra manera, que esta competencia habrá de responder al interés superior del menor (art. 10.1.c).

51. El marco de comunicación entre instrumentos internacionales para el reconocimiento de efectos a la elección del tribunal competente se verá reducido a uno de los supuestos comprendido en el art. 10 del Reglamento 2019/1111, que son los vinculados con el divorcio, la separación judicial o nulidad del matrimonio, por ser la materia coincidente con el CH 96. Pero incluso dentro de este ámbito compartido habrá que tener en cuenta que con arreglo al art. $10 \mathrm{CH} 96$ se requiere que uno de los padres resida habitualmente en el Estado cuyos tribunales se eligen en el momento de iniciar el procedimiento, que es un requisito que en el marco del Reglamento 2019/1111 sirve para demostrar que el menor está estrechamente vinculado con ese Estado, en alternancia con otros, como son que dicho Estado sea el de la antigua residencia habitual del menor o el de su nacionalidad, art. 10.1.a) del Reglamento 2019/1111. En definitiva, y tal como puede observarse, en el marco de las relaciones entre Estados miembros de la UE y Estados parte exclusivamente del CH 96 el reconocimiento de los acuerdos de elección de tribunal competente será más reducido que entre los Estados miembros de la Unión Europea, lo cual puede ser causa de dificultades o errores ${ }^{65}$.

52. En el art. 10 del Reglamento $2019 / 1111$ se ha detallado la forma en que las partes pueden elegir el órgano jurisdiccional competente. Se señala que pueden convenir libremente la competencia,

GonzÁlez BeILfuss, "Prorogation of Jurisdiction”, C. Honorati (ed.), Jurisdiction in matrimonial matters, parental responsibility and international abduction. A Handbook on the application of Brussels IIa Regulation in national courts, Giappichelli editore, Torino, 2017, p. 188. Se añade que se requiere además que esos tribunales tengan una base de competencia judicial internacional para conocer del divorcio, separación o nulidad matrimonial, ya que este aspecto, a diferencia del Reglamento, no se regula en el CH 96, vid. A. Bucher, L'enfant en droit international privé, Helbing \& Lichtenhahn, Bâle, 2003, p. 183.

${ }^{64}$ En este sentido C. González BeIlfuss, "Prorogation of jurisdiction”, op. cit., p. 187.

${ }^{65}$ El carácter más limitado del CH 96 se explica teniendo en cuenta que durante su negociación los Estados de la Unión Europea presionaron para que existiera un cierto paralelismo con la que iba a ser la norma europea, que en ese momento (Convenio de 28 de mayo de 1998, después Reglamento 1347/2000) tenía un carácter más limitado, pues se refería únicamente a las cuestiones de responsabilidad parental vinculadas con la causa matrimonial (Vid. supra nota 31). A la influencia que ejerció la proyectada normativa europea del momento se han referido, entre otros, N. Lowe y M. Nicholls, The 1996 Hague Convention on the protection of children, Jordan Publishing, Bristol, 2012 p. 49. 
al menos en el momento de presentar el asunto ante el órgano jurisdiccional, o aceptarla expresamente durante el procedimiento, siempre que el órgano jurisdiccional se haya asegurado de que todas las partes han sido informadas de su derecho a no aceptar la competencia (art. 10.1.b). Se añade que las partes afectadas deben manifestar por escrito, fechar y firmar el acuerdo de elección de foro, o hacerlo constar en el acta judicial con arreglo al Derecho y el procedimiento nacional, precisándose que se considerará realizada por escrito toda comunicación efectuada por medios electrónicos que proporcione un registro duradero del acuerdo (art. 10.2.I). Se incorpora además una precisión adicional en el sentido de que las personas que pasen a ser partes en el procedimiento, tras la presentación de la demanda ante el órgano jurisdiccional, podrán dar su consentimiento con posterioridad, entendiéndose que existe consentimiento explícito de no haber oposición expresa (art. 10.2.II).

53. Todas estas precisiones son fruto de la influencia que han ejercido los Reglamentos europeos, que en otras materias vinculadas al derecho de familia han regulado la elección del tribunal competente o de la ley aplicable, con unos requisitos formales que ahora se incorporan al Reglamento 2019/1111. También se han tenido muy en cuenta las aclaraciones que ha ido realizando el TJUE en relación con los problemas interpretativos suscitados por el art. 12 del Reglamento 2201/2003 ${ }^{66}$. El CH 96 es más escueto y no realiza tales aclaraciones, por lo que no puede descartarse que se produzcan divergencias aplicativas entre los países de la Unión Europea, cuyos tribunales se verán muy mediatizados por lo dispuesto en el Reglamento 2019/1111, y los países vinculados exclusivamente por el CH 96 , que no lo estarán.

\section{B) La transferencia de la competencia a un órgano jurisdiccional de un Estado parte del CH 96, mejor situado para conocer del asunto}

54. La segunda de las reglas especiales de coordinación prevista en el art. 97.2.b) del Reglamento 2019/1111 se refiere al mecanismo para la remisión del conocimiento del asunto a un órgano jurisdiccional de otro Estado mejor situado para conocer del mismo: con respecto a la transferencia de competencia entre un órgano jurisdiccional de un Estado miembro y un órgano jurisdiccional de un Estado parte del Convenio de La Haya de 1996 en el que no se aplique el presente Reglamento, se aplicarán los artículos 8 y 9 de dicho Convenio. Con esta disposición se deja claro que podrá recurrirse a estos preceptos para colaborar con autoridades de un Estado parte exclusivamente del $\mathrm{CH}$ 96, a pesar de que el menor tenga su residencia habitual en un Estado miembro.

55. Los arts. 8 y 9 CH 96, y sus equivalentes en el Reglamento 2019/1111, que son los arts. 12 y 13 , representan una plasmación de las figuras del forum non conveniens y del forum conveniens, propias de los países de Common $\operatorname{Law}^{67}$. Con estas figuras se flexibilizan o corrigen las normas de competencia judicial internacional, pues se permite al juez un cierto margen de discrecionalidad para conocer o no del asunto. La Unión Europea ha sido tradicionalmente reacia a esta figura, en defensa de la certeza y previsibilidad jurídica que ofrecen unas normas de competencia judicial internacional claramente predeterminadas ${ }^{68}$. Pero en el art. 15 del Reglamento 2201/2003, que ahora se ha convertido en los 12 y 13 del Reglamento 2019/1111, se permitió una cierta discrecionalidad, tomando como modelo el CH 96, y dentro de un estrecho mecanismo de colaboración entre las autoridades implicadas, para que no se viese afectada la seguridad jurídica. En palabras de S. ÁLVAREZ GONZÁLEZ, se trata realmente de un mecanismo que recuerda a la idea de forum conveniens / forum non conveniens, pues se separa

${ }^{66}$ Vid. Sentencias del TJUE de 11 de noviembre de 2014, L y M, as. 656/13, ECLI:EU:C:2014:2364; de 21 de octubre de 2015, Gogova, as. 215/15, ECLI:EU:C:2015:710; y de 19 de abril de 2018, Saponaro, as. 565/16, ECLI:EU:C:2018:265.

$67 \mathrm{Vid}$. P. Lagarade, Informe relativo al Convenio de La Haya de 19 de octubre de 1996 relativo a la competencia, la ley aplicable, el reconocimiento, la ejecución y la cooperación en materia de responsabilidad parental y de medidas de protección de los niños, op. cit., pp. 29 y ss.

${ }^{68}$ En este sentido debe mencionarse la famosa Sentencia del TJCE de 1 de marzo de 2005, Owusu, As. 281/02, ECLI:EU: C:2005:120. 
de estas figuras en virtud de su naturaleza cooperativa bilateral y del establecimiento apriorístico de las alternativas al tribunal normalmente competente ${ }^{69}$.

56. Estas disposiciones tienen por ello un marcado carácter de aplicación inter partes, sobre cuya aplicación en las relaciones entre Estados miembros o entre Estados miembros y terceros Estados, parte exclusivamente del $\mathrm{CH} 96$, no debería haberse suscitado la dificultad interpretativa a la que ahora se ha querido dar respuesta con el art. 97.2.b) del Reglamento 2019/1111. En cualquier caso, las aclaraciones que contribuyen a la mejor articulación de instrumentos internacionales referidos a una misma materia deben ser siempre bienvenidas.

57. El operador jurídico tendrá que ser consciente no obstante de que los arts. 8 y 9 del CH 96 y los arts. 12 y 13 del Reglamento 2019/1111, a pesar de responder a unos mismos principios inspiradores, no son idénticos. Las disposiciones del Reglamento son más precisas en cuanto a cómo se puede poner en marcha este mecanismo de remisión, de oficio o a instancia de parte; en cuanto al ámbito del conocimiento que se transfiere, que puede estar referido al procedimiento o una parte específica del mismo; o en cuanto a los plazos en que debe realizarse esta transferencia, que se pretende que sean breves, fijándose unos claros límite temporales (art. 12, aptdos. $1^{\circ}, 2^{\circ}$ y $3^{\circ}$ ). Por otra parte, no hay una coincidencia plena en relación con las circunstancias en las que se considera en el que el menor tiene un vínculo estrecho con otro Estado, que justifique la remisión de la competencia. En el art. 12.4 del Reglamento 2019/1111 se presentan claramente enumeradas, señalándose expresamente en el Preámbulo que tienen carácter exhaustivo (Considerando 26). El TJUE ya lo había puesto de manifiesto en su Sentencia de 27 de octubre de 2016, D., as 428/1570, a propósito de la interpretación del art. 15 del Reglamento 2201/2003 (p. 51), añadiendo además que su sola presencia no prejuzga por sí sola que estemos ante un órgano jurisdiccional mejor situado (p. 55). En el art. 8.2 CH 96 también se enumeran una serie de circunstancias en las que se considera que el órgano jurisdiccional de otro Estado contratante puede estar mejor situado para conocer del asunto, pero concluyéndose con una fórmula abierta que alude al Estado con el que el niño mantenga un vínculo estrecho.

58. Los jueces de los Estados miembros que son parte en ambos instrumentos internacionales serán los que tengan que manejar estas diferencias, pero será muy probable que la aplicación que hagan de los preceptos del CH 96 acabe viéndose influida por la normativa más precisa y detallada del Reglamento 2019/1111, lo cual puede provocar discrepancias aplicativas con las autoridades de los Estados parte exclusivamente del $\mathrm{CH} 96$.

\section{C) La dualidad de procedimientos con un Estado parte del CH 96}

59. La tercera y última regla especial de articulación se refiere a la dualidad de procedimientos. Conforme al art. 97.2.c): cuando un procedimiento de responsabilidad parental se halle pendiente ante un órgano jurisdiccional de un Estado parte del Convenio de La Haya de 1996 en el que no se aplique el presente Reglamento en el momento en que un órgano jurisdiccional de un Estado miembro esté conociendo de un litigio relativo al mismo menor y con el mismo objeto, se aplicará el artículo 13 de dicho Convenio.

${ }^{69}$ S. Álvarez GonzÁlez, "Responsabilidad parental, transferencia de la competencia a los órganos jurisdiccionales de otro Estado miembro e interés superior del menor. STJUE 27 de octubre de 2016, C-428/15, D”, La Ley Unión Europea, N 43, 30 de Diciembre de 2016, p. 2.

${ }^{70}$ ECLI:EU:C:2016:819. Para un análisis de esta Sentencia vid. S. Álvarez GonZÁLEZ, "Responsabilidad parental, transferencia de la competencia a los órganos jurisdiccionales de otro Estado miembro e interés superior del menor. STJUE 27 de octubre de 2016, C-428/15: D", op. cit., pp. 1 y ss.; B. SÁNCHEZ LÓPEZ, "Responsabilidad parental y la aplicación del forum non conveniens de carácter reglado del artículo 15 del Reglamento (CE) N 2201/2003: la STJUE de 27 de octubre de 2016", Cuadernos de Derecho Transnacional, Vol. 10, No 1, 2018, pp. 639 y ss. 
60. El Reglamento 2201/2003 se ocupa de la litispendencia y acciones dependientes en su art. 19, dedicando específicamente el aptdo. $2^{\circ}$ a las cuestiones de responsabilidad parental. Se trata de una norma diseñada para su aplicación entre Estados miembros y no con respecto a terceros Estados, en relación con los que puede aplicarse el art. $13 \mathrm{CH} 96$ si es parte de este Convenio. Sin embargo, la literalidad del art. 61 del Reglamento 2201/2003 también había planteado dudas sobre la posibilidad de acudir a este precepto en las relaciones con terceros Estados, cuando el menor tuviese su residencia habitual en un Estado miembro ${ }^{71}$. Con la nueva disposición que se introduce en el art. 97.2.c) del Reglamento 2019/1111 queda claro que podrá aplicarse el art. 13 CH 96. En definitiva, las autoridades de los Estados miembros tendrán que aplicar el art. 20 del Reglamento 2019/1111 cuando la dualidad de procedimiento se produzca entre Estados miembros, el art. $13 \mathrm{CH} 1996$ cuando se produzca con un tercer Estado parte de este Convenio, y sus normas nacionales cuando involucre a un tercer Estado que no es parte del CH 96, dado que la reforma del Reglamento 2201/2003 no se ha aprovechado para regular estas situaciones con terceros Estados, a diferencia de lo que sí se ha hecho en el Reglamento 1215/2012.

61. Las autoridades de la Unión Europea, que serán las que tendrán que aplicar los preceptos de un instrumento internacional $u$ otro, además de sus normas nacionales en las circunstancias señaladas, tendrán que acostumbrase a manejar unas disposiciones que responden al mismo objetivo de evitar la duplicidad de procedimientos, pero que al igual que hemos visto en relación con los preceptos anteriormente analizados, no son idénticas.

62. El art. 20.2 del Reglamento 2019/1111 es más exigente en su formulación, pues requiere para su aplicación que se trate de demandas relativas a la responsabilidad parental sobre el mismo menor, que tengan el mismo objeto y la misma causa. Esta triple identidad no se requiere de forma expresa en el art. 13 CH 96. Se observa también que la norma europea prevé que la situación de litispendencia se resuelva en favor del primer órgano jurisdiccional, si se declara competente. El art. $13 \mathrm{CH} 96$, del que se dice en el Informe explicativo del Convenio que está formulado en términos próximos a los utilizados en materia de litispendencia, se refiere a que conocerán las autoridades competentes ante las que se acudió en primer lugar, a menos que declinen su competencia. En definitiva, que se recurre a una fórmula más flexible, con la que se posibilita que la dualidad de procedimientos no siempre se resuelva a favor de que conozcan las autoridades ante las que se acudió en primer lugar ${ }^{72}$.

63. Por otra parte, tanto para el funcionamiento del art. 20 del Reglamento 2019/1111 como del art. $13 \mathrm{CH}$ 96, resulta fundamental determinar el órgano jurisdiccional ante el que se ha iniciado el procedimiento en primer lugar ${ }^{73}$. En la Unión Europea ya se tiene experiencia con las dificultades que pueden surgir en torno a esta cuestión, debido a las peculiaridades procesales de los distintos Estados miembros. Los Reglamentos suelen incorporar por ello un precepto para determinar el momento de iniciación del procedimiento (art. 16 del Reglamento 2201/2003, ahora art. 17 del Reglamento 2019/1111), que no han evitado, sin embargo, que en ocasiones se haya tenido que acudir al TJUE para resolver casos dudosos ${ }^{74}$. Estas dificultades, como puede imaginarse, serán susceptibles de plantearse con Estados parte exclusivamente del $\mathrm{CH} 96$, con la dificultad añadida de que estos países no están vinculados por la jurisprudencia del TJUE.

\footnotetext{
${ }^{71}$ T. KRUGER, "Brussels IIa recast moving forward", op. cit., p. 473.

72 P. LAGARDE, Informe explicativo relativo al Convenio de La Haya de 19 de octubre de 1996 relativo a la competencia, la ley aplicable, el reconocimiento, la ejecución y la cooperación en materia de responsabilidad parental y de medidas de protección de los niños, op. cit., p. 40.

${ }^{73}$ En el marco del Reglamento 2019/1111 y para su aplicación entre los Estados miembros se ha introducido, como novedad, una alteración en el funcionamiento de la prioridad cuando uno de los órganos jurisdiccionales tenga competencia exclusiva en virtud del art. 10 (arts. 20, aptdos. $4^{\circ}$ y $5^{\circ}$ ).

${ }^{74} \mathrm{Vid}$. Auto del TJUE de 16 de julio de 2015, P., As. 507/14, ECLI:EU:C:2015:512; y Auto del TJUE de 22 de junio de 2016, M.H. y M.H., As. 173/16, ECLI:EU:C:2016:542
} 


\section{Conclusiones}

64. En la actualidad, muchas de las dificultades que entraña el Derecho internacional privado como disciplina jurídica están causadas por el complejo entramado de disposiciones normativas susceptibles de aplicarse a cada caso concreto. Junto a disposiciones de origen interno, repartidas en nuestro país en una pluralidad de normas, el operador jurídico tiene que acostumbrarse a manejar un número creciente de instrumentos internacionales, que provienen de la Unión Europea u otros organismos codificadores, entre los que destaca la Conferencia de La Haya de Derecho Internacional Privado. Ello conlleva que muchas veces el esfuerzo del operador jurídico tenga que centrarse en identificar la norma aplicable a un caso concreto, más que en entender y aplicar lo que dice la norma en cuestión.

65. Este problema ocurre especialmente en aquellos sectores jurídicos donde han proliferado las iniciativas unificadoras a nivel internacional, entre los que cabría mencionar las cuestiones de responsabilidad parental y protección de menores, que ahora nos ocupan. La Conferencia de La Haya ha elaborado diversos convenios internacionales en materia de protección de menores, en algunos casos sustituyendo a convenios previamente aprobados, que no han impedido que la Unión Europea también quisiera entrar a regular esta cuestión.

66. El CH 96 y el Reglamento 2019/1111 regulan la competencia judicial internacional, el reconocimiento y ejecución de resoluciones, así como la cooperación de autoridades. El CH 96 se ocupa también de las cuestiones de ley aplicable. Se trata de sectores que funcionan de forma diferente, porque junto al carácter inter partes de las normas sobre cooperación de autoridades y reconocimiento y ejecución de resoluciones, se encuentra el carácter erga omnes de las normas sobre ley aplicable. En el primer caso, el carácter inter partes facilita la articulación normativa, al tiempo que justifica que los Estados miembros de la Unión Europea quieran dotarse de una normativa específica y más eficaz entre ellos. En el segundo, el carácter erga omnes de las normas de conflicto lleva a que sea imposible la convivencia con un instrumento internacional paralelo, y a que la Unión Europea haya optado por no regular este sector del Derecho internacional privado, a fin de mantener la cooperación con la Conferencia de la Haya de Derecho Internacional Privado. Sin embargo, las normas de competencia judicial internacional no responden ni a un modelo ni a otro, lo que ha llevado a que haya sido precisamente en este sector donde se han planteado los mayores problemas de convivencia entre el Reglamento 2201/2003 y el CH 96.

67. La reforma que introduce el Reglamento 2019/1111 en el precepto dedicado a regular las relaciones con el $\mathrm{CH} 96$ debe ser bienvenida, porque contribuye a clarificar las relaciones entre estos dos instrumentos en el sector de la competencia judicial internacional. Cierto es que los operadores jurídicos tendrán que acostumbrarse, en función de las circunstancias del caso, a tener que aplicar las disposiciones de uno u otro instrumento, que son parecidas, pero no idénticas. La ventaja, al menos, es que sus esfuerzos podrán centrarse en lo que es el contenido específico de la norma a aplicar, sin el problema añadido de la falta de claridad sobre cuál debe ser la norma aplicable. 